OPEN ACCESS

Edited by:

Muller Fabbri,

Children's Hospital Los Angeles,

United States

Reviewed by:

Ivan Vannini,

Istituto Scientifico Romagnolo per lo Studio e la Cura dei Tumori (IRCCS),

Italy

Nicoletta Potenza,

Università degli Studi della Campania

"Luigi Vanvitelli", Italy

*Correspondence:

Seong Lin Teoh

teohseonglin@yahoo.com.my

Specialty section:

This article was submitted to

$R N A$,

a section of the journa

Frontiers in Genetics

Received: 30 November 2017 Accepted: 29 January 2018

Published: 14 February 2018

Citation:

Soliman AM, Das S, Abd Ghafar N and Teoh SL (2018) Role

of MicroRNA in Proliferation Phase

of Wound Healing. Front. Genet. 9:38.

doi: 10.3389/fgene.2018.00038

\section{Role of MicroRNA in Proliferation Phase of Wound Healing}

\author{
Amro M. Soliman, Srijit Das, Norzana Abd Ghafar and Seong Lin Teoh* \\ Department of Anatomy, Universiti Kebangsaan Malaysia Medical Centre, Kuala Lumpur, Malaysia
}

Wound healing is a complex biological process that is generally composed of four phases: hemostasis, inflammation, proliferation, and remodeling. The proliferation phase is crucial for effective healing compared to other phases. Many critical events occur during this phase, i.e., migration of fibroblasts, re-epithelialization, angiogenesis and wound contraction. Chronic wounds are common and are considered a major public health problem. Therefore, there is the increasing need to discover new therapeutic strategies. MicroRNA (miRNA) research in the field of wound healing is in its early phase, but the knowledge of the recent discoveries is essential for developing effective therapies for the treatment of chronic wounds. In this review, we focused on recently discovered miRNAs which are involved in the proliferation phase of wound healing in the past few years and their role in wound healing.

Keywords: angiogenesis, chronic wound, healing, microRNA, re-epithelialization

\section{WOUND HEALING}

Skin is the outer anatomical guard protecting us against the external environment. Skin is formed of 3 layers: epidermis, dermis and subcutaneous layer. Following skin injury, the synergetic interaction between different dermal cells in a process regulated at different levels is essential (Reinke and Sorg, 2012). The process of wound healing generally consists of four sequential but overlapping phases: (i) Hemostasis phase in which, platelets and coagulation factors lead to clotting and reduce blood loss (Kibe et al., 2017); (ii) Inflammation phase is characterized by infiltration of various inflammatory cells to the wound site to eliminate the pathogens and secrete cytokines and growth factors (Eming et al., 2014; Kibe et al., 2017); (iii) Proliferation phase is the rebuilding of extracellular matrix (ECM) at the wound site which involves angiogenesis, granulation tissue formation, collagen fibers deposition, epithelialisation and wound retraction (Young and McNaught, 2011); (iv) Remodeling phase is the maturation of scar tissue where type III collagen is replaced with type I collagen (Gurtner and Evans, 2000).

\section{PROLIFERATION PHASE OF WOUND HEALING}

Proliferation phase lasts from 3 days up to 2 weeks following skin injury. Collectively, the proliferative phase is achieved through three main steps: re-epithelialization, angiogenesis and the formation of granulation tissue.

\section{Re-epithelialization}

In re-epithelialization, keratinocytes at the wound edges proliferate actively and migrate to reestablish coverage of the wound site (Cheng et al., 2016). In addition, stem cells from hair follicles or 
sweat glands in the vicinity of the wound also contribute to re-epithelialization (Miller et al., 1998; Roh and Lyle, 2006; Lau et al., 2009). Keratinocytes disengage the desmosome/hemidesmosome junctions and reorganize their cytoskeleton in order to migrate over the wound site (Cheng et al., 2016). Keratinocytes revert back to the normal phenotype after seizing migration and attach firmly to the re-established basement membrane and underlying dermis (Cheng et al., 2016).

\section{Angiogenesis}

Angiogenesis is a complex process of growth of new vessels from pre-existing blood vessels. This process is initiated in the early healing process when the hemostatic plug has formed and as platelets release transforming growth factor (TGF)- $\beta$, plateletderived growth factor (PDGF) and fibroblast growth factor (FGF) (Heun et al., 2017). Together with hypoxia-inducible factor-1 (HIF-1) and vascular endothelial growth factor (VEGF) which are released in response to hypoxia, these transcription factors and growth factors induce expression of several angiogenic genes, neovascularization and the repair of damaged blood vessels at the wound site (Young and McNaught, 2011; Heun et al., 2017). As angiogenesis proceeds, a rich vascular bed in the wound site that has many fold more capillaries than does normal tissue (DiPietro, 2016).

\section{Granulation Tissue Formation}

After skin wounding, proliferation and migration of fibroblasts to the wound site are induced by growth factors released from the platelets (Young and McNaught, 2011). In addition, fibroblasts also derived from bone-marrow-derived mesenchymal stem cell (Sasaki et al., 2008). Fibroblasts secrete a loose matrix of ECM proteins (i.e., glycosaminoglycans, proteoglycans and hyaluronic acid), fibronectin and collagen (Singh et al., 2004; Young and McNaught, 2011). The resulting vascularized fibrous tissue replacing the hemostatic clot at the wound site is known as granulation tissue.

Following the formation of granulation tissue, fibroblasts change to $\alpha$-smooth muscle actin-expressing myofibroblast phenotype, which is triggered by mechanical tension, focal adhesion protein Hic-5 and activated TGF- $\beta$ (Hinz et al., 2001; Varney et al., 2016). Myofibroblast plays a major role in wound contraction, which begins approximately 7 days following injury, occurring at a rate of $0.75 \mathrm{~mm} /$ day (Young and McNaught, 2011). The final outcome will fill the wound gap with granulation tissue covered by surface epithelium, and the wound is ready for the last phase (remodeling).

\section{MICRORNA}

MicroRNA (miRNA) is a small non-coding RNA molecule which consists of about 18-25 nucleotides in length (Parikh et al., 2014). The non-coding RNAs are RNA which do not code for proteins. However, some of them, including the ribosomal RNA, transfer RNA, small nuclear RNAs and small nucleolar RNAs, were reported to control various cell functions such as mRNA translation and regulation of gene expression (Mattick and Makunin, 2006) The non-coding RNA can be divided into short and long non-coding RNA depending on the number of nucleotides. Long non-coding RNAs are similar to mRNA and they range from 200 nucleotides to 100 kilobases in length. They are expressed in specific tissues to perform certain functions. Long non-coding RNAs include the antisense such as Oct4-pg5 and the brain-associated BC200 (Gibb et al., 2011). On the other hand, many researchers discovered different small non-coding regulatory RNAs (18-100 nucleotides in length) in both animals and plants which mainly include snoRNAs and miRNAs (Mattick and Makunin, 2006). miRNA as one of the small non-coding RNAs was discovered first in the early 1990s by Victor Ambros through studies with the lin-4 gene in the nematode Caenorhabditis elegans. In cells, miRNA plays a major role in the regulation of gene expression and controlling various processes such as metabolism, cell proliferation, differentiation and apoptosis (Gregersen et al., 2010). miRNA regulate gene expression through binding to the $3^{\prime}$ untranslated region (UTR) of mRNA. This binding leads to mRNA degradation which in turn leads to inhibition of protein translation (Nicoloso et al., 2009). Junk DNA was transcribed giving rise to different classes of non-coding RNA, including miRNAs, as a major part of human DNA which was thought to be with no function. Nowadays scientists have realized that a major part of the junk DNA is highly related to coding of miRNAs.

miRNAs are synthesized from primary miRNAs (pri-miRNAs) in two stages by the action of two RNase III-type proteins: Drosha in the nucleus and Dicer in the cytoplasm (Kim et al., 2009). Genes for miRNAs are transcribed to primary miRNA (primiRNA), which is then processed within the nucleus to precursor miRNA (pre-miRNA) by a class 2 RNase III enzyme (Drosha). Next, the pre-miRNAs are transported from the nucleus to the cytoplasm where they are processed to become mature miRNAs by an RNase III-type protein (Dicer). miRNAs are attached to the Argonaute protein to produce the RNA-induced silencing complex (RISC) (Wahid et al., 2010). Several mechanisms were reported to regulate the biogenesis and expression of miRNAs (Kim, 2005). Those mechanisms include the single nucleotide polymorphisms (SNPs), which are induced by alternations in the nucleotides sequences of genes coding for miRNA. SNPs control the biogenesis and functions of miRNA by changing the coding sequences of variant miRNAs (Mishra et al., 2008). Moreover, RNA editing, one of the major pathways of RNA modification at the post-transcriptional level, can lead to different miRNA expression. For instance, almost $16 \%$ of pri-miRNAs synthesize is induced by A-to-I nucleotide editing (Kawahara et al., 2008). Some miRNA genes are affected by hypermethylation thus; nearly $10 \%$ miRNAs expression is regulated by DNA methylation. Meanwhile, inhibition of methylation resulted in a decreased in expression of certain miRNA (Han et al., 2007). The function of miRNAs is mainly related to the regulation of gene expression. A miRNA is complementary to a part of one or more mRNAs. Base pairing of RISC with the target RNA leads to inhibition of protein translation and/or mRNA degradation. miRNAs mainly bind their mRNA targets via a sequence between the 2nd and 8 th nucleotides of their $5^{\prime}$ proximal region (Kawasaki 
and Taira, 2004). It is noteworthy to mention that miRNA interferes with the target gene expression through repression of mRNA translation or degradation of mRNA achieved by deadenylation from $3^{\prime}$ end and/or decapping from $5^{\prime}$ end. A previous study reported that $48 \%$ miRNA target genes are principally regulated by translation repression, $29 \%$ are controlled by mRNA degradation, and $23 \%$ are regulated by both mechanisms (Jin and Xiao, 2015). Moreover, in certain miRNA, the expression is promptly increased to millions of copies per cell aiming to degrade its target genes (Giraldez et al., 2006). In addition to the ability of miRNA to downregulate their target genes, they are also capable of upregulating the expression of genes. miRNA complex promotes the expression of target mRNAs similar to miRNA-mediated downregulation. The mRNA expression may be stimulated either by the direct effect of miRNA or indirectly through miRNA-mediated repression of other inhibitory miRNAs targeting the same gene (Valinezhad Orang et al., 2014). miRNA biogenesis and mechanism of action are shown in Figure 1.

\section{miRNA AND CHRONIC WOUND HEALING}

Chronic wounds such as leg ulcers, pressure ulcers, and diabetic foot ulcers (DFU) are common. Millions of people worldwide suffer from chronic wounds and their complications and thus are considered a major public health problem. In Germany, an epidemiology study revealed that there were 786,407 prevalent and 196,602 incident chronic wounds in the year of 2012 (Heyer et al., 2016). Nearly 3 million US citizens are suffering from pressure ulcer, while much more are suffering from venous ulcers (Shilo et al., 2007). It was also estimated that 15\% of diabetic patients will suffer from diabetic ulcers, which is considered as a major source of morbidity and the main cause of hospitalization in diabetic patients (Aalaa et al., 2012; Leone et al., 2012; Shahbazian et al., 2013). Treating these chronic wounds is estimated to cost about $\$ 5-10$ billion each year in the United States (Kuehn, 2007). In Singapore, the annual direct cost of chronic wound management in a tertiary hospital was about SGD 4.59 million while the total indirect costs (i.e., income loss due to hospitalization stay amounted to SGD 0.86 million (Tan et al., 2016).

Several studies have investigated the role of miRNA in skin metabolism. The following miRNAs were found to be heavily expressed in the skin: miR-152, miR-143, miR-126, miR-21, miR27a, miR-214, miR-16, miR-203, miR-125b, miR-34a, miR-205, miR-27b, miR-30b, miR-125a, miR-191 and miR-200 family (Yi et al., 2006). Numerous studies have investigated the expression levels of various miRNAs in different phases of wound healing; suggesting miRNAs have a potential role in wound healing. In this review, we focus on the role of miRNA in the 3 main processes in the proliferation phase of wound healing: re-epithelialization, angiogenesis, and granulation tissue formation.

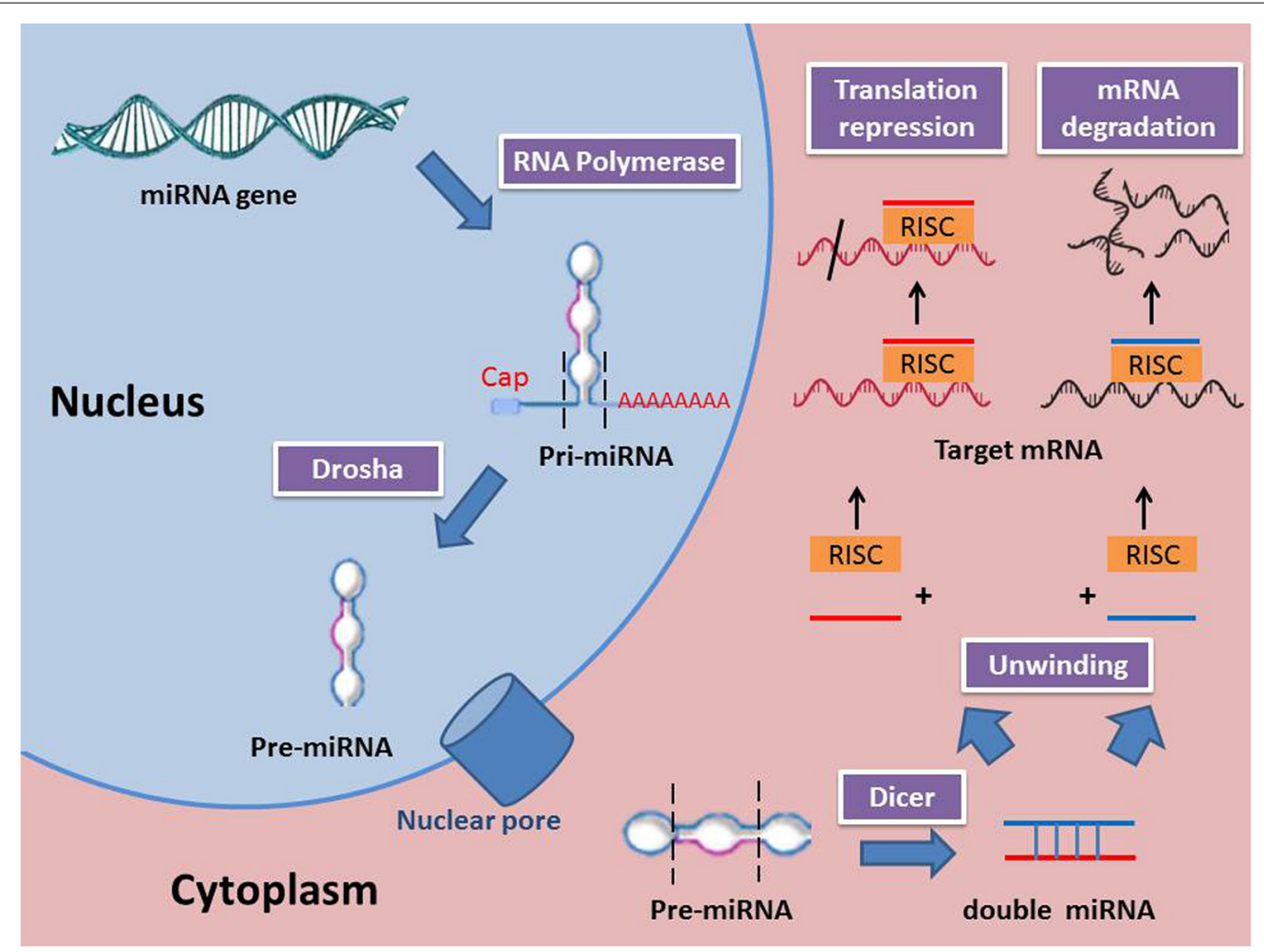

FIGURE 1 | miRNA biogenesis and mechanisms of action (RISC, RNA-induced silencing complex; Pri-miRNA, Primary miRNA; Pre-miRNA, precursor miRNA). 


\section{Role of miRNA in Re-epithelialization}

The re-epithelialization process is considered a crucial step in wound healing (Serarslan et al., 2007). Collectively, it involves migration of keratinocytes to cover the newly formed granulation tissue. Several studies have investigated the role of miRNA in regulating the re-epithelialization process (Table 1).

\section{miR-21}

miR-21 has been reported that miRNA plays a crucial role in cell proliferation, EMT and migration through silencing its target genes (Gabriely et al., 2008; Krichevsky and Gabriely, 2009). miR21 promotes migration of cancer cells by targeting Reversion Inducing Cysteine-Rich Protein with Kazal motifs (RECK), TIMP metallopeptidase inhibitor 3 (TIMP3), and T-Cell Lymphoma Invasion And Metastasis 1 (TIAM1) genes (Gabriely et al., 2008; Cottonham et al., 2010). Recent studies demonstrated that miR21 was highly expressed in the epidermis and hair follicle (Yi et al., 2006). Over-expression of miR-21 enhanced keratinocyte migration while miR-21 knockdown led to a remarkable delay in the re-epithelialization process (Yang et al., 2011). This may suggest that miR-21 is crucial for keratinocyte migration and reepithelialization. TIMP3 and TIAM1 were identified as the direct target genes of miR-21 indicating that these genes are related to keratinocyte migration (Yang et al., 2011).

\section{miR-31}

miR-31 was reported to have a role in cell differentiation and hair growth (Mardaryev et al., 2010; Peng et al., 2012). Furthermore, the up-regulation of miR-31 has been reported in several skin conditions characterized by excessive keratinocyte proliferation such as psoriasis (Morhenn et al., 2013; Xu et al., 2013) and squamous cell carcinoma (Bruegger et al., 2013; Wang A. et al., 2014). The expression of miR-31 was gradually upregulated in keratinocytes of wound edges in both inflammation and proliferative phases of wound healing. miR-31 promoted keratinocytes proliferation and migration by blocking epithelial membrane protein 1 (Li D. et al., 2015). Moreover, miR-31 expression was stimulated by Transforming Growth Factor Beta 2 (TGF- $\beta 2$ ), which was significantly expressed in the wound area (Li D. et al., 2015).

\section{miR-203}

miR-203 is considered the most abundant keratinocyte-related miRNA in the epidermis (Sonkoly et al., 2007). Down-regulation of miRNA-203 promotes epithelial-mesenchymal transition (EMT) in various cancers (Wellner et al., 2009; Saini et al.,
2011). miR-203 possesses an anti-proliferative activity through targeting the mRNA of the transcription factor p63 (Lena et al., 2008; Yi et al., 2008). P63 was proven to have a role in keratinocyte proliferation in the normal and diseased skin (Senoo et al., 2007; Lena et al., 2012). Two new targets of miR203, Ras-related nuclear protein (RAN) and Ras Association and Pleckstrin Homology Domains 1 (RAPH1) are also found to be essential for the re-epithelialization process (Viticchie et al., 2012). miR-203 may control the expression of target proteins that are responsible for keratinocytes proliferation and migration. miR-203 was proven along with miR-210 to be key regulators of keratinocyte proliferation and migration (Deppe et al., 2016). Following injury, miR-203 expression was down-regulated in highly proliferating keratinocytes. Injections of antagomiR-203 in the dorsal skin of newborn mice increased the expression of its target mRNAs: RAN and RAPH1 (Viticchie et al., 2012). Inhibitors of both miR-203 and miR-210 could represent a potential therapy to enhance the re-epithelialization process.

\section{miR-204}

miR-204 is highly expressed in the epithelium of different eye tissues including the cornea, lens, and retina (Ryan et al., 2006; Wang et al., 2010). It has been reported that miR-204 is crucial for the development of both lens and retinal (Conte et al., 2010). Moreover, miR-204 is essential for the homeostasis of retinal pigment epithelium (Wang et al., 2010). Although miR204 is heavily detected in the cornea, its expression was downregulation during corneal wound healing. Increased expression levels of miR-204 lead to inhibition of cell proliferation and migration (An et al., 2015). Therefore, down-regulation of miRNA-204 may enhance epithelial wound healing. A few target genes of miRNA-204 have been reported such as SMAD Family Member 4 (SMAD4) and Sirtuin 1 (Wang et al., 2013a; Zhang et al., 2013). Furthermore, SIRT1 is an essential gene target of miR-204 in both corneal cell culture and mice corneal wound healing (An et al., 2015). In a recent study, it was observed that SIRT1 enhanced proliferation and migration epithelial cells (Wang et al., 2013c). This may support the fact that targeting of SIRT1 and SMAD4 by miR-204 leads to inhibition of proliferation and migration epithelial cells.

\section{miR-205}

Keratinocyte-specific miR-205 is expressed abundantly in epithelial tissues, where it can be detected in the basal and superficial layers of stratified squamous epithelium (Ryan et al., 2006; Yi et al., 2006). This indicates that miR-205 may

TABLE 1 | miRNAs involved in the re-epithelialization process in wound healing.

\begin{tabular}{|c|c|c|c|}
\hline miRNA & Effect & Target & Reference \\
\hline miR-21 & Enhances keratinocyte migration. & TIMP3, TIAM1 & Yang et al., 2011 \\
\hline miR-31 & Promotes keratinocyte proliferation and migration. & EMP-1 & Li D. et al., 2015 \\
\hline miR-203 & Inhibits keratinocyte proliferation and migration. & RAN, RAPH1, P63 & Viticchie et al., 2012; Deppe et al., 2016 \\
\hline miR-204 & Inhibits epithelial cells proliferation and migration. & SMAD4, SIRT1 & Wang et al., 2013c; An et al., 2015 \\
\hline miR-205 & Enhances epithelial cells proliferation and migration. & SHIP2 & Yu et al., 2010 \\
\hline miR-210 & Inhibits proliferation of epithelial cells. & E2F3 & Giannakakis et al., 2008; Biswas et al., 2010 \\
\hline
\end{tabular}


be essential for development and homeostasis of epithelial cells (Gregory et al., 2008). It has been reported that miR-205 suppressed $\mathrm{SH}$-containing phosphoinositide 5-phosphatase 2 (SHIP2) in human epidermal keratinocytes and corneal epithelial keratinocytes cell lines (Yu et al., 2008). SHIP2 is a lipid phosphatase enzyme that dephosphorylates phosphatidylinositol 3,4,5-triphosphate (PIP3), a critical second messenger in various pathways including Akt and phosphoinositide-dependent kinase-1 which is essential for keratinocytes migration (Aman et al., 1998; Cantley, 2002). miR-205 plays a major role in keratinocyte migration thus, re-epithelialization process. miR205 expression is down-regulated in migrating epithelial tongue during wound healing (Wang et al., 2016). This was proved by a study which used antagomiR-205 to reduce the expression levels of miR-205 in human epithelial cell lines. Treatment of human epithelial cell lines with antagomiR-205 increased SHIP2 levels and decreased the ability of the cells to close a scratch wounds (Yu et al., 2010). In addition, topical inhibition of miR-205 by administrating pluronic gel containing antagomiR205 promotes keratinocyte migration in mouse wound model in vivo (Wang et al., 2016). Down-regulation of miR-205 resulted in an increased phosphorylation of the actin-severing protein cofilin, and a corresponding diminution of filamentous actin which suppressed the keratinocytes migration ( $\mathrm{Yu}$ et al., 2010).

\section{miR-210}

Over-expression of miR-210 is a consistent feature of the hypoxia response (Corn, 2008; Huang and Zuo, 2014). Seven signature miRNAs (including miR-210) were found to be associated with low oxygen tension (Blick et al., 2015). HIF$1 \alpha$ is a transcription factor which regulates the hypoxic cycle of the cell has been found to arrest cell proliferation of keratinocytes (Scortegagna et al., 2009). Recent studies observed that HIF-1 $\alpha$ may also serve as a transcription factor for the expression of miRNAs (Sen et al., 2009). Another study observed that ischemic wounds possessed increased expression levels of the HIF-1 $\alpha$-dependent miR-210 (Biswas et al., 2010). Furthermore, expression of E2F transcription factor 3 (E2F3) gene, a target gene of miR-210), which is essential for epithelial cells proliferation was significantly lower in ischemic wounds (Giannakakis et al., 2008). These observations clarify that miR210 may inhibit the proliferation of epithelial cells in chronic wounds.

\section{Role of miRNA in Angiogenesis Process}

Angiogenesis process is extremely vital for wound healing as it provides the essential oxygen and nutrients necessary for healing process (Li et al., 2003). Chronic wounds are characterized by depressed angiogenesis which is mainly attributed to the impairment of migration of the endothelial cells through blood vessel wall to form vascular sprouts and reduced level of VEGF in diabetic wounds (Brem and Tomic-Canic, 2007; Gallagher et al., 2007; Quattrini et al., 2008). miRNAs involved in angiogenesis are summarized in Table 2.

\section{miR-1}

VEGF-A is considered the primary gene regulating angiogenesis process (Maeda et al., 1996). In human cancers, VEGF-A levels are usually associated with bad prognosis and high mortality rate (Juttner et al., 2006; Suzuki et al., 2010). miR-1 was found to suppress VEGF-A leading to inhibition of angiogenesis in tumor tissue (Stahlhut et al., 2012). The expression of miR-1 was frequently down-regulated in tumor tissues compared to corresponding normal tissues. Meanwhile, up-regulation of miR1 remarkably inhibited the tube formation and endothelial cells proliferation by suppressing the expression of VEGF-A (Xie et al., 2017).

\section{miR-21}

miR-21 was reported to be over-expressed in multiple tumors in the last decade (Cheng and Zhang, 2010; Li et al., 2012). Moreover, recent studies showed that miR-21 is considered as a potent anti-angiogenic factor through the inhibition of proliferation and migration of endothelial cells (Jin et al., 2013; Jiang et al., 2015). miR-21 directly down-regulated the expression of both Phosphatase and Tensin Homolog (PTEN) and SMAD7 genes which are crucial in the regulation of angiogenesis process. Thus, over-expression of miR-21 inhibited endothelial cells proliferation, migration and tube formation (Wang et al., 2017).

TABLE 2 | miRNAs involved in the angiogenesis process of wound healing.

\begin{tabular}{llll}
\hline miRNA & Effect & Target & Reference \\
\hline miR-1 & Inhibits tube formation and endothelial cells proliferation. & VEGF-A & Xie et al., 2017 \\
miR-21 & Inhibits of proliferation and migration of endothelial cells. & PTEN, SMAD7 & Jin et al., 2013; Jiang et al., 2015 \\
miR-23a & Increases vascular permeability and cellular migration. & PHD1, 2 & Hsu et al., 2017 \\
miR-29b & Inhibits neovascularization. & VEGF, STAT3 & Li et al., 2017b,c \\
miR-126 & Enhances migration and repair of endothelial cells. & SPRED1 & Cao et al., 2017 \\
miR-133a/b & Stimulates proliferation and branch formation of endothelial cells. & TGF-31 & Sun et al., 2017 \\
miR-146a & Enhances new blood vessels formation. & VEGF, Pak1 & Seo et al., 2017 \\
miR-210 & Increases proliferation, migration and tube formation of endothelial cells. & Efna3 & Hu et al., 2010; Wang et al., 2017 \\
miR-218 & Inhibits neovascularization. & ROBO1 & Zhang X. et al., 2017 \\
miR-377 & Inhibits angiogenesis. & CD133, VEGF & Li et al., 2017a,b \\
miR-939 & Disrupts vascular integrity and inhibits angiogenesis. & $\gamma$-catenin & Hou et al., 2017 \\
miR-4530 & Promotes angiogenesis. & VASH1 & Zhang T. et al., 2017
\end{tabular}




\section{miR-23a}

miR-23a is expressed in many cancers including breast cancer and colon cancer as a key regulator of cellular apoptosis and proliferation (Li et al., 2013; Lian et al., 2013). A study showed that miR-23a was up-regulated in cells of lung cancer under hypoxic conditions leading to blocking its target prolyl hydroxylase 1 and 2 (PHD1 and 2) genes. Blocking of PHD1 and 2 led to the accumulation of HIF-1 $\alpha$ in endothelial cells which in turn stimulated angiogenesis. Furthermore, miR-23a increased vascular permeability and cellular migration. On the other hand, down-regulation of miR-23a reduced angiogenesis process in cancer cells (Hsu et al., 2017).

\section{miR-29b}

miR-29b is a member of miR-29 family members which are known for their ability to induce transcriptional regulation, epigenetic modification and cell apoptosis (Han et al., 2010; Nguyen et al., 2011). Expression of miR-29b is weak in malignant cells as they possess anti-tumor functions. miR-29b is currently identified as a fundamental regulator of EMT which is considered a common pathway of cancer metastasis and chemotherapy resistance (Yan et al., 2015). A recent study has investigated the role of miR-29b in angiogenesis of breast cancer. The results showed that miR-29b was down-regulated in tumor tissues ( $\mathrm{Li}$ et al., 2017b). Moreover, miR-29b showed anti-angiogenesis and anti-tumorigenesis activities by suppressing vascularization of cancer tissue. It was suggested that miR-29b targeted Akt3 pathway and inhibited Akt3 mediated VEGF (Li et al., 2017b). These results may support the role miR-29b as an inhibitor of angiogenesis process. Another study reported that up-regulation of miR-29b suppressed the angiogenesis of cervical cancer cells in vitro and inhibited neovascularization in vivo through targeting Signal Transducer and Activator of Transcription 3 (STAT3) gene. On the other hand, down-regulation of miRNA$29 \mathrm{~b}$ could enhance angiogenesis of cancer cells (Li et al., 2017c).

\section{miR-126}

miR-126 plays a role in the vascular protection of endothelial cells (Zernecke et al., 2009). miR-126 can act as a tumor suppressor factor in the case of acute myeloid leukemia or act as an oncogene in case of colon cancer (Meister and Schmidt, 2010). miRNA-126 may support cancer progression through the promotion of angiogenesis process (Meister and Schmidt, 2010). It has been demonstrated that cigarette smoking released endothelial cells microparticles (EMPs) that contain miR-126. The increased miRNA-126-enriched EMPs promoted angiogenesis and endothelial homeostasis through enhancing migration and repair of endothelial cells (Cao et al., 2017). Sprouty Related EVH1 Domain Containing 1 (SPRED1) mRNA was identified as a gene target for miR-126. The miR-126 expression level in the peripheral blood of diabetic patients with DFU was lower than diabetic patients without DFU and the nondiabetic population (Zhang J. et al., 2017). Following maggot debridement therapy, the miR-126 expression was increased in diabetic patients with DFU (Zhang J. et al., 2017). The use of exosomes derived from miR-126-3p over-expressed synovial mesenchymal stem cells encapsulated in hydrogels in diabetic wound model successfully promote re-epithelialization and accelerate angiogenesis (Li et al., 2016).

\section{miR-133a/b}

In the human genome, there are three identified miRNA133 species: miR-133a-1, miR-133a-2, and miR-133b found on chromosomes 18, 20 and 6 respectively (Ivey et al., 2008). TGF- $\beta 1$ gene is considered as one of the major targets of miR-133 (Shan et al., 2009). miR-133a and miR-133b expression were significantly decreased in lung tissue after hyperoxia. It was observed that transfection of lung cells with miR-133a/b mimics restored cell proliferation and branch formation of endothelial cells. Moreover, miR-133a/b mimics stimulated expression of angiogenic factors in endothelial cells (Sun et al., 2017). The previous observations suggest that decreased expression of miR133 inhibits angiogenesis process.

\section{miR-146a}

miR-146a is a well-identified miRNA which regulates inflammation and proliferation processes (Sonkoly et al., 2008). It has been reported that miR-146a was up-regulated in osteoarthritis (Yamasaki et al., 2009) and breast cancer (Lanczky et al., 2016). miR-146a targets P21 Activated Kinase 1 (PAK)1 gene, which in turn stimulated VEGF expression and formation of vascular branches. Moreover, miRNA-146a reduced fibrosis and enhanced new blood vessels formation (Seo et al., 2017). This suggests that miRNA-146 could regulate VEGF expression and promote angiogenesis process.

\section{miR-210}

miR-210 has been reported to be commonly up-regulated in cells of the ischemic heart and cardiac tumors (Devlin et al., 2011). Recent studies proved that over-expression of miR-210 stimulated angiogenesis and inhibited apoptosis of cardiac cells in case of myocardial infarction (Hu et al., 2010). Another study showed that miR-210 remarkably enhanced angiogenesis and cardiac function in ischemic heart disease (Wang et al., 2017). miR-210 was found to be up-regulated in mesenchymal stem cells which were used for treating myocardial infarction model. Moreover, miR-210 increased the proliferation, migration and tube formation of endothelial cells. Ephrin A3 (EFNA3) gene was identified as the target gene for miRNA-210 (Wang et al., 2017). The previously mentioned data elaborates the role of miR-210 as an angiogenic factor.

\section{miR-218}

miR-218 is well-known to be expressed by motor neurons and its down-regulation can result in hyperexcitability and neurodegeneration due to its potential role in homeostasis of the nervous system (Amin et al., 2015). Furthermore, miR-218 was identified in cancer cells such as squamous cell carcinoma (Uesugi et al., 2011). miR-218 was found to have a potential anti-tumor function in bladder cancer (Tatarano et al., 2011) and nasopharyngeal carcinoma (Alajez et al., 2011). A recent study reported that miR-218 inhibited neovascularization process in vitro. It was suggested that mechanism of action of miR-218 was mediated by targeting Roundabout Guidance Receptor 1 (ROBO1) gene (Zhang X. et al., 2017). Based on previous results, 
we may consider miR-218 as an anti-angiogenic therapy in case of cancers. However, miR-218 inhibitor could promote angiogenesis process.

\section{miR-377}

miR-377 is a crucial miRNA that plays a critical role in the pathogenesis of certain diseases such as diabetic nephropathy (Wang et al., 2008). miR-377 was down-regulated in specific cancers including ovarian cancer, prostatic cancer and lymphoma (Zhang et al., 2008; Arribas et al., 2013). Moreover, miR-377 was proven to inhibit proliferation and invasion of some human cancers such as glioblastoma (Zhang et al., 2014). Both in vitro and in vivo study showed that miR-377 over-expression inhibited the growth and angiogenesis of esophageal cancer while its downregulation showed opposite effects (Li et al., 2017a).

\section{miR-939}

miR-939 is a recently identified miRNA which was found to promote the cell proliferation in ovarian cancer (Ying et al., 2015). However, in breast cancer, miR-939 inhibited cell proliferation and metastasis (Di Modica et al., 2017). These findings may predict the variant roles of miRNA in different cancers. A recent study revealed that miRNA-939 was downregulated in ischemic heart disease patients and it was found to disrupt vascular integrity and inhibit angiogenesis through targeting $\gamma$-catenin gene (Hou et al., 2017).

\section{$\operatorname{miR}-4530$}

miR-4530 expression was down-regulated in patients with diabetic retinopathy. Interestingly, miR-4530 possessed the ability to stimulate angiogenesis in endothelial cells (Ding et al., 2016). Vasohibin-1 (VASH1) gene was identified as one of the targets of miRNA-4530 (Zhang T. et al., 2017). VASH1 gene is over-expressed in endothelial cells leading to inhibition of angiogenesis process as a negative feedback (Watanabe et al., 2004; Kimura et al., 2009). Thus, by suppressing VASH1, miR4530 may promote angiogenesis. miR-4530 was demonstrated to promote angiogenesis in breast cancer and to suppress breast cancer by inhibiting cell proliferation and induction of apoptosis (Zhang T. et al., 2017).

\section{Role of miRNA in Granulation Tissue Formation}

The formation of the granulation tissue is a significant step in wound healing as it regulates and organizes the growth of the wound tissue (Asahara et al., 1999; Schultz and Wysocki, 2009). In this phase, granulation tissue formed is composed of different molecules including glycosaminoglycans, proteoglycans, and hyaluronic acid. Numerous miRNAs have been reported to support the formation of granulation tissues (Table 3 ).

\section{miR-29}

miR-29 was reported to have a significant role in the regulation of some biological processes including cell apoptosis (Kole et al., 2011) and proliferation (Wei et al., 2013). Various studies identified multiple target genes for miR-29 including genes coding for ECM component such as collagen and elastin genes (Kriegel et al., 2012; Wang et al., 2013b). The miR-29b expression was significantly decreased during the healing process while the heat shock protein 47 (HSP47, a post-transcriptional target of miR-29b,) level was markedly increased, following full-thickness excisional wound and burn wound models (Zhu et al., 2016). The local administration of miR-29b lentivirus inhibits HSP47 expression, collagen synthesis, and angiogenesis during skin wound healing (Zhu et al., 2016). In addition, miR-29b reduces excessive scar formation by inhibition of TGF- $\beta 1 / \mathrm{Smad} / \mathrm{CTGF}$ signaling pathway (Guo et al., 2017).

\section{miR-98}

miR-98 has a role in the development of variant cancers. It inhibits tumor angiogenesis and invasion by decreasing the matrix metalloproteinase-11 enzyme levels (Siragam et al., 2012). A recent study showed that miRNA-98 can regulate collagen, type I alpha 1 (Coll $\alpha 1)$ gene expression in skin fibroblasts. Following transfection of fibroblasts with miR98 mimic, there was a remarkable decline in Colla1 gene expression leading to declining in the cell viability and increased apoptosis. On the other hand, transfection of cells with miR-98 inhibitor resulted in opposite effects (Bi et al., 2017). Fibroblast apoptosis is known as a key regulator in the development of normal and pathological scar (Scharstuhl et al., 2009). So that, miR-98 may play a role in wound healing by enhancing fibroblast proliferation and controlling scar formation.

\section{miR-141-3p}

miR-141-3p was reported to suppress the growth and metastasis of prostatic tumor (Liu et al., 2017). Similarly, miR-141-3p inhibited invasion and metastasis of glioma (Peng et al., 2016). The over-expression of miR-141-3p inhibited cell proliferation and migration of skin fibroblasts as well as enhanced cell apoptosis, while its down-regulation resulted in the opposite effects (Feng et al., 2017).

\section{miR-185}

miR-185 located on chromosome 22, was reported in various types of cancer including lung cancer (Li S. et al., 2015), hepatoma

TABLE 3 | miRNAs involved in granulation tissue formation in wound healing.

\begin{tabular}{lllc}
\hline miRNA & Effect & Target & Reference \\
\hline miR-29 & Inhibits collagen synthesis and angiogenesis. & HSP47 \\
miR-98 & Decreases viability and increases apoptosis of fibroblasts. & Col1a1 \\
miR-141-3p & Inhibits cell proliferation, migration of fibroblasts and enhances cell apoptosis. & - & Guo et al., 2017 \\
miR-185 & Inhibits growth of fibroblasts. & TGF- $\beta$ 1, Col-1 et al., 2017
\end{tabular}


(Qadir et al., 2014), and stomach cancer (Tan et al., 2014). miR185 has a role in wound healing and fibroblast migration (Yang and Yee, 2014). A recent study suggested that over-expression of miR-185 inhibited the growth of fibroblasts, through direct targeting of TGF- $\beta 1$ and Col-1 genes, both serve a critical role in the development of hypertrophic scarring (Xiao et al., 2017).

\section{THERAPEUTIC STRATEGIES FOR WOUND HEALING AND FUTURE DIRECTIONS}

miRNA-based therapy will be a revolution in the advanced therapy for chronic wounds as they will be able to modulate a group of genes through the use of a single miRNA. The base upon which therapeutic miRNAs will be used relays on the ability to reduce the damaging miRNAs and upregulate the levels of the beneficial miRNAs which could be achieved by several methods. Up-regulation of potentially beneficial miRNAs can be achieved by using synthetic doublestranded oligonucleotides called miRNA mimics. Mimics are double-stranded RNA which consists of the same sequence of the target miRNA in one strand which will be incorporated into the RISC complex (Fasanaro et al., 2010). The downregulation of potentially harmful miRNAs can be achieved by complementary oligonucleotides antagomiRs which act as competitive inhibitors through binding to the mature miRNA or lead to inhibition of miRNA maturation by binding to the pre-miRNA. Successful delivery of either mimics or antagomiRs depends mainly on their resistance to destruction in different tissues and binding affinity to the target miRNA. Therefore, chemical modifications of the oligonucleotides are required. Collectively, miRNA regulators can be delivered to mammalian tissues through either intravenous injection of oligonucleotides or conjugation of those oligonucleotides with other lipophilic molecules as high-density lipoproteins to facilitate their uptake by cells (Fasanaro et al., 2010). Further studies investigating the role of different miRNAs in the phases of wound healing along with screening their target genes are recommended. A better understanding of the molecular mechanism of wound healing may provide better treatment and advanced solutions to chronic wounds. Various miRNA delivery systems were discovered in the last decade to convey miRNAs of choice into cells of wound

\section{REFERENCES}

Aalaa, M., Malazy, O. T., Sanjari, M., Peimani, M., and Mohajeri-Tehrani, M. (2012). Nurses' role in diabetic foot prevention and care; a review. J. Diabetes Metab. Disord. 11:24. doi: 10.1186/2251-6581-11-24

Alajez, N. M., Lenarduzzi, M., Ito, E., Hui, A. B., Shi, W., Bruce, J., et al. (2011). MiR-218 suppresses nasopharyngeal cancer progression through downregulation of survivin and the SLIT2-ROBO1 pathway. Cancer Res. 71, 2381-2391. doi: 10.1158/0008-5472.CAN-10-2754

Aman, M. J., Lamkin, T. D., Okada, H., Kurosaki, T., and Ravichandran, K. S. (1998). The inositol phosphatase SHIP inhibits Akt/PKB activation in B cells. J. Biol. Chem. 273, 33922-33928. doi: 10.1074/jbc.273.51.33922

Amin, N. D., Bai, G., Klug, J. R., Bonanomi, D., Pankratz, M. T., Gifford, W. D., et al. (2015). Loss of motoneuron-specific microRNA-218 causes systemic neuromuscular failure. Science 350, 1525-1529. doi: 10.1126/science.aad2509 tissue aiming to promote wound healing. Among those delivery systems, viral vectors are considered the most common and effective, despite few disadvantages including mutagenesis and restricted capacity for genetic material. Meanwhile, non-viral miRNA delivery systems, such as cationic polymers, peptides, and liposomes, are recognized by their lower toxicity, water solubility, and resistance to endonucleases or phagocytosis. These vectors are loaded with miRNAs and transfected into cutaneous cells to induce their function (Meng et al., 2017). Researchers conducted several experiments to deliver certain beneficial miRNAs into wound tissue. A previous study revealed significant effects of antihypoxamiR encapsulated lipid nanoparticles on ischemia during wound healing (Ghatak et al., 2016). Others reported that delivery of miR-27b mimics may improve wound healing through stimulating the bone marrow-derived angiogenic cell function in patients with type 2 diabetes mellitus (Wang J.M. et al., 2014). Systematic injection of anti-miR-26a improved angiogenesis process in mice through increasing SMAD1 gene expression (Icli et al., 2013).

\section{CONCLUSION}

Numerous studies have demonstrated the important role of miRNA in wound healing, especially in chronic wounds. miRNAs are regulatory molecules that contribute to numerous aspects and phases of wound healing. They may play an important role to accelerate the wound healing process in chronic wounds.

\section{AUTHOR CONTRIBUTIONS}

Conceptual framework and design: NAG and SD. Searched reference and drafted the article: AS and ST. Critically revised the article: NAG and SD. All authors reviewed and accepted the final version of the article.

\section{ACKNOWLEDGMENTS}

The authors acknowledge the help received from the Secretariat for Medical Research \& Innovation, Universiti Kebangsaan Malaysia Medical Centre.

An, J., Chen, X., Chen, W., Liang, R., Reinach, P. S., Yan, D., et al. (2015). MicroRNA expression profile and the role of miR-204 in corneal wound healing. Invest. Ophthalmol. Vis. Sci. 56, 3673-3683. doi: 10.1167/iovs.1516467

Arribas, A. J., Gomez-Abad, C., Sanchez-Beato, M., Martinez, N., Dilisio, L., Casado, F., et al. (2013). Splenic marginal zone lymphoma: comprehensive analysis of gene expression and miRNA profiling. Mod. Pathol. 26, 889-901. doi: 10.1038/modpathol.2012.220

Asahara, T., Masuda, H., Takahashi, T., Kalka, C., Pastore, C., Silver, M., et al. (1999). Bone marrow origin of endothelial progenitor cells responsible for postnatal vasculogenesis in physiological and pathological neovascularization. Circ. Res. 85, 221-228. doi: 10.1161/01.RES.85.3.221

Bi, S., Chai, L., Yuan, X., Cao, C., and Li, S. (2017). MicroRNA-98 inhibits the cell proliferation of human hypertrophic scar fibroblasts via targeting Col1A1. Biol. Res. 50:22. doi: 10.1186/s40659-017-0127-6 
Biswas, S., Roy, S., Banerjee, J., Hussain, S. R., Khanna, S., Meenakshisundaram, G., et al. (2010). Hypoxia inducible microRNA 210 attenuates keratinocyte proliferation and impairs closure in a murine model of ischemic wounds. Proc. Natl. Acad. Sci. U.S.A. 107, 6976-6981. doi: 10.1073/pnas.1001 653107

Blick, C., Ramachandran, A., McCormick, R., Wigfield, S., Cranston, D., Catto, J., et al. (2015). Identification of a hypoxia-regulated miRNA signature in bladder cancer and a role for miR-145 in hypoxia-dependent apoptosis. Br. J. Cancer 113, 634-644. doi: 10.1038/bjc.2015.203

Brem, H., and Tomic-Canic, M. (2007). Cellular and molecular basis of wound healing in diabetes. J. Clin. Invest. 117, 1219-1222. doi: 10.1172/JCI32169

Bruegger, C., Kempf, W., Spoerri, I., Arnold, A. W., Itin, P. H., and Burger, B. (2013). MicroRNA expression differs in cutaneous squamous cell carcinomas and healthy skin of immunocompetent individuals. Exp. Dermatol. 22, 426-428. doi: $10.1111 /$ exd.12153

Cantley, L. C. (2002). The phosphoinositide 3-kinase pathway. Science 296, 1655-1657. doi: 10.1126/science.296.5573.1655

Cao, D., Serban, K., and Petrache, I. (2017). Effects of miR-126-enriched endothelial microparticles released during cigarette smoke exposure on endothelial cell migration and proliferation. Am. J. Respir. Crit. Care Med. 195:A1216.

Cheng, F., Shen, Y., Mohanasundaram, P., Lindstrom, M., Ivaska, J., Ny, T., et al. (2016). Vimentin coordinates fibroblast proliferation and keratinocyte differentiation in wound healing via TGF- $\beta$-Slug signaling. Proc. Natl. Acad. Sci. U.S.A. 113, E4320-E4327. doi: 10.1073/pnas.1519197113

Cheng, Y., and Zhang, C. (2010). MicroRNA-21 in cardiovascular disease. J. Cardiovasc. Transl. Res. 3, 251-255. doi: 10.1007/s12265-010-9169-7

Conte, I., Carrella, S., Avellino, R., Karali, M., Marco-Ferreres, R., Bovolenta, P., et al. (2010). miR-204 is required for lens and retinal development via Meis2 targeting. Proc. Natl. Acad. Sci. U.S.A. 107, 15491-15496. doi: 10.1073/pnas. 0914785107

Corn, P. G. (2008). Hypoxic regulation of miR-210: shrinking targets expand HIF-1's influence. Cancer Biol. Ther. 7, 265-267. doi: 10.4161/cbt.7.2.5745

Cottonham, C. L., Kaneko, S., and Xu, L. (2010). miR-21 and miR-31 converge on TIAM1 to regulate migration and invasion of colon carcinoma cells. J. Biol. Chem. 285, 35293-35302. doi: 10.1074/jbc.M110.160069

Deppe, J., Steinritz, D., Santovito, D., Egea, V., Schmidt, A., Weber, C., et al. (2016). Upregulation of miR-203 and miR-210 affect growth and differentiation of keratinocytes after exposure to sulfur mustard in normoxia and hypoxia. Toxicol. Lett. 244, 81-87. doi: 10.1016/j.toxlet.2015.09.012

Devlin, C., Greco, S., Martelli, F., and Ivan, M. (2011). miR-210: more than a silent player in hypoxia. IUBMB Life 63, 94-100. doi: 10.1002/iub.427

Di Modica, M., Regondi, V., Sandri, M., Iorio, M. V., Zanetti, A., Tagliabue, E., et al. (2017). Breast cancer-secreted miR-939 downregulates VE-cadherin and destroys the barrier function of endothelial monolayers. Cancer Lett. 384, 94-100. doi: 10.1016/j.canlet.2016.09.013

Ding, L., Ai, D., Wu, R., Zhang, T., Jing, L., Lu, J., et al. (2016). Identification of the differential expression of serum microRNA in type 2 diabetes. Biosci. Biotechnol. Biochem. 80, 461-465. doi: 10.1080/09168451.2015.1107460

DiPietro, L. A. (2016). Angiogenesis and wound repair: when enough is enough. J. Leukoc. Biol. 100, 979-984. doi: 10.1189/jlb.4MR0316-102R

Eming, S. A., Martin, P., and Tomic-Canic, M. (2014). Wound repair and regeneration: mechanisms, signaling, and translation. Sci. Transl. Med. 6:265sr6. doi: 10.1126/scitranslmed.3009337

Fasanaro, P., Greco, S., Ivan, M., Capogrossi, M. C., and Martelli, F. (2010). microRNA: emerging therapeutic targets in acute ischemic diseases. Pharmacol. Ther. 125, 92-104. doi: 10.1016/j.pharmthera.2009.10.003

Feng, J., Xue, S., Pang, Q., Rang, Z., and Cui, F. (2017). miR-141-3p inhibits fibroblast proliferation and migration by targeting GAB1 in keloids. Biochem. Biophys. Res. Commun. 490, 302-308. doi: 10.1016/j.bbrc.2017.06.040

Gabriely, G., Wurdinger, T., Kesari, S., Esau, C. C., Burchard, J., Linsley, P. S., et al. (2008). MicroRNA 21 promotes glioma invasion by targeting matrix metalloproteinase regulators. Mol. Cell. Biol. 28, 5369-5380. doi: 10.1128/MCB. 00479-08

Gallagher, K. A., Liu, Z. J., Xiao, M., Chen, H., Goldstein, L. J., Buerk, D. G., et al. (2007). Diabetic impairments in NO-mediated endothelial progenitor cell mobilization and homing are reversed by hyperoxia and SDF-1 alpha. J. Clin. Invest. 117, 1249-1259. doi: 10.1172/JCI29710
Ghatak, S., Li, J., Chan, Y. C., Gnyawali, S. C., Steen, E., Yung, B. C., et al. (2016). AntihypoxamiR functionalized gramicidin lipid nanoparticles rescue against ischemic memory improving cutaneous wound healing. Nanomedicine 12, 1827-1831. doi: 10.1016/j.nano.2016.03.004

Giannakakis, A., Sandaltzopoulos, R., Greshock, J., Liang, S., Huang, J., Hasegawa, K., et al. (2008). miR-210 links hypoxia with cell cycle regulation and is deleted in human epithelial ovarian cancer. Cancer Biol. Ther. 7, 255-264. doi: $10.4161 /$ cbt.7.2.5297

Gibb, E. A., Brown, C. J., and Lam, W. L. (2011). The functional role of long noncoding RNA in human carcinomas. Mol. Cancer 10:38. doi: 10.1186/1476-459810-38

Giraldez, A. J., Mishima, Y., Rihel, J., Grocock, R. J., Van Dongen, S., Inoue, K., et al. (2006). Zebrafish MiR-430 promotes deadenylation and clearance of maternal mRNAs. Science 312, 75-79. doi: 10.1126/science.1122689

Gregersen, L. H., Jacobsen, A. B., Frankel, L. B., Wen, J., Krogh, A., and Lund, A. H. (2010). MicroRNA-145 targets YES and STAT1 in colon cancer cells. PLOS ONE 5:e8836. doi: 10.1371/journal.pone.0008836

Gregory, P. A., Bert, A. G., Paterson, E. L., Barry, S. C., Tsykin, A., Farshid, G., et al. (2008). The miR-200 family and miR-205 regulate epithelial to mesenchymal transition by targeting ZEB1 and SIP1. Nat. Cell Biol. 10, 593-601. doi: 10.1038/ ncb 1722

Guo, J., Lin, Q., Shao, Y., Rong, L., and Zhang, D. (2017). miR-29b promotes skin wound healing and reduces excessive scar formation by inhibition of the TGFB1/Smad/CTGF signaling pathway. Can. J. Physiol. Pharmacol. 95, 437-442. doi: $10.1139 /$ cjpp-2016-0248

Gurtner, G. C., and Evans, G. R. (2000). Advances in head and neck reconstruction. Plast. Reconstr. Surg. 106, 672-682.

Han, L., Witmer, P. D., Casey, E., Valle, D., and Sukumar, S. (2007). DNA methylation regulates MicroRNA expression. Cancer Biol. Ther. 6, 1284-1288.

Han, Y. C., Park, C. Y., Bhagat, G., Zhang, J., Wang, Y., Fan, J. B., et al. (2010). microRNA-29a induces aberrant self-renewal capacity in hematopoietic progenitors, biased myeloid development, and acute myeloid leukemia. J. Exp. Med. 207, 475-489. doi: 10.1084/jem.20090831

Heun, Y., Pogoda, K., Anton, M., Pircher, J., Pfeifer, A., Woernle, M., et al. (2017). HIF- $1 \alpha$ dependent wound healing angiogenesis in vivo can be controlled by site-specific lentiviral magnetic targeting of SHP-2. Mol. Ther. 25, 1616-1627. doi: 10.1016/j.ymthe.2017.04.007

Heyer, K., Herberger, K., Protz, K., Glaeske, G., and Augustin, M. (2016). Epidemiology of chronic wounds in Germany: analysis of statutory health insurance data. Wound Repair Regen. 24, 434-442. doi: 10.1111/wrr.12387

Hinz, B., Mastrangelo, D., Iselin, C. E., Chaponnier, C., and Gabbiani, G. (2001). Mechanical tension controls granulation tissue contractile activity and myofibroblast differentiation. Am. J. Pathol. 159, 1009-1020. doi: 10.1016/ S0002-9440(10)61776-2

Hou, S., Fang, M., Zhu, Q., Liu, Y., Liu, L., and Li, X. (2017). MicroRNA-939 governs vascular integrity and angiogenesis through targeting $\gamma$-catenin in endothelial cells. Biochem. Biophys. Res. Commun. 484, 27-33. doi: 10.1016/j. bbrc.2017.01.085

Hsu, Y. L., Hung, J. Y., Chang, W. A., Lin, Y. S., Pan, Y. C., Tsai, P. H., et al. (2017). Hypoxic lung cancer-secreted exosomal miR-23a increased angiogenesis and vascular permeability by targeting prolyl hydroxylase and tight junction protein ZO-1. Oncogene 36, 4929-4942. doi: 10.1038/onc.2017.105

Hu, S., Huang, M., Li, Z., Jia, F., Ghosh, Z., Lijkwan, M. A., et al. (2010). MicroRNA210 as a novel therapy for treatment of ischemic heart disease. Circulation 122(11 Suppl. 1), S124-S131. doi: 10.1161/CIRCULATIONAHA.109.92 8424

Huang, X., and Zuo, J. (2014). Emerging roles of miR-210 and other non-coding RNAs in the hypoxic response. Acta Biochim. Biophys. Sin. 46, 220-232. doi: 10.1093/abbs/gmt141

Icli, B., Wara, A. K., Moslehi, J., Sun, X., Plovie, E., Cahill, M., et al. (2013). MicroRNA-26a regulates pathological and physiological angiogenesis by targeting BMP/SMAD1 signaling. Circ. Res. 113, 1231-1241. doi: 10.1161/ CIRCRESAHA.113.301780

Ivey, K. N., Muth, A., Arnold, J., King, F. W., Yeh, R. F., Fish, J. E., et al. (2008). MicroRNA regulation of cell lineages in mouse and human embryonic stem cells. Cell Stem Cell 2, 219-229. doi: 10.1016/j.stem.2008.01.016

Jiang, F. S., Tian, S. S., Lu, J. J., Ding, X. H., Qian, C. D., Ding, B., et al. (2015). Cardamonin regulates miR-21 expression and suppresses angiogenesis 
induced by vascular endothelial growth factor. Biomed Res. Int. 2015:501581. doi: $10.1155 / 2015 / 501581$

Jin, C., Zhao, Y., Yu, L., Xu, S., and Fu, G. (2013). MicroRNA-21 mediates the rapamycin-induced suppression of endothelial proliferation and migration. FEBS Lett. 587, 378-385. doi: 10.1016/j.febslet.2012.12.021

Jin, H. Y., and Xiao, C. (2015). MicroRNA mechanisms of action: what have we learned from mice? Front. Genet. 6:328. doi: 10.3389/fgene.2015.00328

Juttner, S., Wissmann, C., Jons, T., Vieth, M., Hertel, J., Gretschel, S., et al. (2006). Vascular endothelial growth factor-D and its receptor VEGFR-3: two novel independent prognostic markers in gastric adenocarcinoma. J. Clin. Oncol. 24, 228-240. doi: 10.1200/JCO.2004.00.3467

Kawahara, Y., Megraw, M., Kreider, E., Iizasa, H., Valente, L., Hatzigeorgiou, A. G., et al. (2008). Frequency and fate of microRNA editing in human brain. Nucleic Acids Res. 36, 5270-5280. doi: 10.1093/nar/gkn479

Kawasaki, H., and Taira, K. (2004). MicroRNA-196 inhibits HOXB8 expression in myeloid differentiation of HL60 cells. Nucleic Acids Symp. Ser. 48, 211-212. doi: 10.1093/nass/48.1.211

Kibe, T., Koga, T., Nishihara, K., Fuchigami, T., Yoshimura, T., Taguchi, T., et al. (2017). Examination of the early wound healing process under different wound dressing conditions. Oral Surg. Oral Med. Oral Pathol. Oral Radiol. 123, 310-319. doi: 10.1016/j.0ooo.2016.10.023

Kim, V. N. (2005). MicroRNA biogenesis: coordinated cropping and dicing. Nat. Rev. Mol. Cell Biol. 6, 376-385. doi: 10.1038/nrm1644

Kim, V. N., Han, J., and Siomi, M. C. (2009). Biogenesis of small RNAs in animals. Nat. Rev. Mol. Cell Biol. 10, 126-139. doi: 10.1038/nrm2632

Kimura, H., Miyashita, H., Suzuki, Y., Kobayashi, M., Watanabe, K., Sonoda, H., et al. (2009). Distinctive localization and opposed roles of vasohibin-1 and vasohibin-2 in the regulation of angiogenesis. Blood 113, 4810-4818. doi: 10.1182/blood-2008-07-170316

Kole, A. J., Swahari, V., Hammond, S. M., and Deshmukh, M. (2011). miR-29b is activated during neuronal maturation and targets $\mathrm{BH} 3$-only genes to restrict apoptosis. Genes Dev. 25, 125-130. doi: 10.1101/gad.1975411

Krichevsky, A. M., and Gabriely, G. (2009). miR-21: a small multi-faceted RNA. J. Cell. Mol. Med. 13, 39-53. doi: 10.1111/j.1582-4934.2008.00556.x

Kriegel, A. J., Liu, Y., Fang, Y., Ding, X., and Liang, M. (2012). The miR-29 family: genomics, cell biology, and relevance to renal and cardiovascular injury. Physiol. Genomics 44, 237-244. doi: 10.1152/physiolgenomics.00141.2011

Kuehn, B. M. (2007). Chronic wound care guidelines issued. JAMA 297, 938-939. doi: 10.1001/jama.297.9.938

Lanczky, A., Nagy, A., Bottai, G., Munkacsy, G., Szabo, A., Santarpia, L., et al. (2016). miRpower: a web-tool to validate survival-associated miRNAs utilizing expression data from 2178 breast cancer patients. Breast Cancer Res. Treat. 160, 439-446. doi: 10.1007/s10549-016-4013-7

Lau, K., Paus, R., Tiede, S., Day, P., and Bayat, A. (2009). Exploring the role of stem cells in cutaneous wound healing. Exp. Dermatol. 18, 921-933. doi: $10.1111 / j .1600-0625.2009 .00942 . x$

Lena, A. M., Mancini, M., Rivetti di Val Cervo, P., Saintigny, G., Mahe, C., Melino, G., et al. (2012). MicroRNA-191 triggers keratinocytes senescence by SATB1 and CDK6 downregulation. Biochem. Biophys. Res. Commun. 423, 509-514. doi: 10.1016/j.bbrc.2012.05.153

Lena, A. M., Shalom-Feuerstein, R., Rivetti di Val Cervo, P., Aberdam, D., Knight, R. A., Melino, G., et al. (2008). miR-203 represses 'stemness' by repressing DeltaNp63. Cell Death Differ. 15, 1187-1195. doi: 10.1038/cdd.2008.69

Leone, S., Pascale, R., Vitale, M., and Esposito, S. (2012). Epidemiology of diabetic foot. Infez. Med. 20(Suppl. 1), 8-13.

Li, B., Xu, W. W., Han, L., Chan, K. T., Tsao, S. W., Lee, N. P. Y., et al. (2017a). MicroRNA-377 suppresses initiation and progression of esophageal cancer by inhibiting CD133 and VEGF. Oncogene 36, 3986-4000. doi: 10.1038/onc.2017. 29

Li, D., Li, X. I., Wang, A., Meisgen, F., Pivarcsi, A., Sonkoly, E., et al. (2015). MicroRNA-31 promotes skin wound healing by enhancing keratinocyte proliferation and migration. J. Invest. Dermatol. 135, 1676-1685. doi: 10.1038/ jid.2015.48

Li, J., Zhang, Y. P., and Kirsner, R. S. (2003). Angiogenesis in wound repair: angiogenic growth factors and the extracellular matrix. Microsc. Res. Tech. 60, 107-114. doi: 10.1002/jemt. 10249

Li, M., Ke, Q.-F., Tao, S.-C., Guo, S.-C., Rui, B.-Y., and Guo, Y.-P. (2016). Fabrication of hydroxyapatite/chitosan composite hydrogels loaded with exosomes derived from miR-126-3p overexpressed synovial mesenchymal stem cells for diabetic chronic wound healing. J. Mater. Chem. B 4, 6830-6841. doi: 10.1039/C6TB01560C

Li, S., Liang, Z., Xu, L., and Zou, F. (2012). MicroRNA-21: a ubiquitously expressed pro-survival factor in cancer and other diseases. Mol. Cell. Biochem. 360, 147-158. doi: 10.1007/s11010-011-1052-6

Li, S., Ma, Y., Hou, X., Liu, Y., Li, K., Xu, S., et al. (2015). MiR-185 acts as a tumor suppressor by targeting AKT1 in non-small cell lung cancer cells. Int. J. Clin. Exp. Pathol. 8, 11854-11862.

Li, X., Liu, X., Xu, W., Zhou, P., Gao, P., Jiang, S., et al. (2013). c-MYC-regulated miR-23a/24-2/27a cluster promotes mammary carcinoma cell invasion and hepatic metastasis by targeting Sprouty2. J. Biol. Chem. 288, 18121-18133. doi: 10.1074/jbc.M113.478560

Li, Y., Cai, B., Shen, L., Dong, Y., Lu, Q., Sun, S., et al. (2017b). MiRNA-29b suppresses tumor growth through simultaneously inhibiting angiogenesis and tumorigenesis by targeting Akt3. Cancer Lett. 397, 111-119. doi: 10.1016/j. canlet.2017.03.032

Li, Y., Zhang, Z., Xiao, Z., Lin, Y., Luo, T., Zhou, Q., et al. (2017c). Chemotherapymediated miR-29b expression inhibits the invasion and angiogenesis of cervical cancer. Oncotarget 8, 14655-14665. doi: 10.18632/oncotarget.14738

Lian, S., Shi, R., Bai, T., Liu, Y., Miao, W., Wang, H., et al. (2013). Anti-miRNA-23a oligonucleotide suppresses glioma cells growth by targeting apoptotic protease activating factor-1. Curr. Pharm. Des. 19, 6382-6389.

Liu, C., Liu, R., Zhang, D., Deng, Q., Liu, B., Chao, H. P., et al. (2017). MicroRNA141 suppresses prostate cancer stem cells and metastasis by targeting a cohort of pro-metastasis genes. Nat. Commun. 8:14270. doi: 10.1038/ncomms14270

Maeda, K., Chung, Y. S., Ogawa, Y., Takatsuka, S., Kang, S. M., Ogawa, M., et al. (1996). Prognostic value of vascular endothelial growth factor expression in gastric carcinoma. Cancer 77, 858-863.

Mardaryev, A. N., Ahmed, M. I., Vlahov, N. V., Fessing, M. Y., Gill, J. H., Sharov, A. A., et al. (2010). Micro-RNA-31 controls hair cycle-associated changes in gene expression programs of the skin and hair follicle. FASEB J. 24, 3869-3881. doi: 10.1096/fj.10-160663

Mattick, J. S., and Makunin, I. V. (2006). Non-coding RNA. Hum. Mol. Genet. 15(Suppl. 1), 17-29. doi: 10.1093/hmg/ddl046

Meister, J., and Schmidt, M. H. (2010). miR-126 and miR-126*: new players in cancer. ScientificWorldJournal 10, 2090-2100. doi: 10.1100/tsw.2010.198

Meng, Z., Zhou, D., Gao, Y., Zeng, M., and Wang, W. (2017). miRNA delivery for skin wound healing. Adv. Drug Deliv. Rev. 17, 30314-30319. doi: 10.1016/j.addr. 2017.12.011

Miller, S. J., Burke, E. M., Rader, M. D., Coulombe, P. A., and Lavker, R. M. (1998). Re-epithelialization of porcine skin by the sweat apparatus. J. Invest. Dermatol. 110, 13-19. doi: 10.1046/j.1523-1747.1998.00087.x

Mishra, P. J., Mishra, P. J., Banerjee, D., and Bertino, J. R. (2008). MiRSNPs or MiR-polymorphisms, new players in microRNA mediated regulation of the cell: introducing microRNA pharmacogenomics. Cell Cycle 7, 853-858. doi: $10.4161 /$ cc.7.7.5666

Morhenn, V. B., Nelson, T. E., and Gruol, D. L. (2013). The rate of wound healing is increased in psoriasis. J. Dermatol. Sci. 72, 87-92. doi: 10.1016/j.jdermsci.2013. 06.001

Nguyen, T., Kuo, C., Nicholl, M. B., Sim, M. S., Turner, R. R., Morton, D. L., et al. (2011). Downregulation of microRNA-29c is associated with hypermethylation of tumor-related genes and disease outcome in cutaneous melanoma. Epigenetics 6, 388-394. doi: 10.4161/epi.6.3.14056

Nicoloso, M. S., Spizzo, R., Shimizu, M., Rossi, S., and Calin, G. A. (2009). MicroRNAs-the micro steering wheel of tumour metastases. Nat. Rev. Cancer 9, 293-302. doi: 10.1038/nrc2619

Parikh, A., Lee, C., Joseph, P., Marchini, S., Baccarini, A., Kolev, V., et al. (2014). microRNA-181a has a critical role in ovarian cancer progression through the regulation of the epithelial-mesenchymal transition. Nat. Commun. 5:2977. doi: $10.1038 /$ ncomms 3977

Peng, H., Kaplan, N., Hamanaka, R. B., Katsnelson, J., Blatt, H., Yang, W., et al. (2012). microRNA-31/factor-inhibiting hypoxia-inducible factor 1 nexus regulates keratinocyte differentiation. Proc. Natl. Acad. Sci. U.S.A. 109, 14030-14034. doi: 10.1073/pnas.1111292109

Peng, T., Zhang, S., Li, W., Fu, S., Luan, Y., and Zuo, L. (2016). MicroRNA-141 inhibits glioma cells growth and metastasis by targeting TGF- $\beta 2$. Am. J. Transl. Res. 8, 3513-3521. 
Qadir, X. V., Han, C., Lu, D., Zhang, J., and Wu, T. (2014). miR-185 inhibits hepatocellular carcinoma growth by targeting the DNMT1/PTEN/Akt pathway. Am. J. Pathol. 184, 2355-2364. doi: 10.1016/j.ajpath.2014.05.004

Quattrini, C., Jeziorska, M., Boulton, A. J., and Malik, R. A. (2008). Reduced vascular endothelial growth factor expression and intra-epidermal nerve fiber loss in human diabetic neuropathy. Diabetes Care 31, 140-145. doi: 10.2337/ dc07-1556

Reinke, J. M., and Sorg, H. (2012). Wound repair and regeneration. Eur. Surg. Res. 49, 35-43. doi: 10.1159/000339613

Roh, C., and Lyle, S. (2006). Cutaneous stem cells and wound healing. Pediatr. Res. 59(4 Pt 2), 100R-103R. doi: 10.1203/01.pdr.0000203572.51876.ba

Ryan, D. G., Oliveira-Fernandes, M., and Lavker, R. M. (2006). MicroRNAs of the mammalian eye display distinct and overlapping tissue specificity. Mol. Vis. 12, 1175-1184.

Saini, S., Majid, S., Yamamura, S., Tabatabai, L., Suh, S. O., Shahryari, V., et al. (2011). Regulatory role of miR-203 in prostate cancer progression and metastasis. Clin. Cancer Res. 17, 5287-5298. doi: 10.1158/1078-0432.CCR-102619

Sasaki, M., Abe, R., Fujita, Y., Ando, S., Inokuma, D., and Shimizu, H. (2008). Mesenchymal stem cells are recruited into wounded skin and contribute to wound repair by transdifferentiation into multiple skin cell type. J. Immunol. 180, 2581-2587. doi: 10.4049/jimmunol.180.4.2581

Scharstuhl, A., Mutsaers, H. A., Pennings, S. W., Szarek, W. A., Russel, F. G., and Wagener, F. A. (2009). Curcumin-induced fibroblast apoptosis and in vitro wound contraction are regulated by antioxidants and heme oxygenase: implications for scar formation. J. Cell. Mol. Med. 13, 712-725. doi: 10.1111/j. 1582-4934.2008.00339.x

Schultz, G. S., and Wysocki, A. (2009). Interactions between extracellular matrix and growth factors in wound healing. Wound Repair Regen. 17, 153-162. doi: 10.1111/j.1524-475X.2009.00466.x

Scortegagna, M., Martin, R. J., Kladney, R. D., Neumann, R. G., and Arbeit, J. M. (2009). Hypoxia-inducible factor-1alpha suppresses squamous carcinogenic progression and epithelial-mesenchymal transition. Cancer Res. 69, 2638-2646. doi: 10.1158/0008-5472.CAN-08-3643

Sen, C. K., Gordillo, G. M., Khanna, S., and Roy, S. (2009). Micromanaging vascular biology: tiny microRNAs play big band. J. Vasc. Res. 46, 527-540. doi: 10.1159/000226221

Senoo, M., Pinto, F., Crum, C. P., and McKeon, F. (2007). p63 Is essential for the proliferative potential of stem cells in stratified epithelia. Cell 129, 523-536. doi: 10.1016/j.cell.2007.02.045

Seo, H. H., Lee, S. Y., Lee, C. Y., Kim, R., Kim, P., Oh, S., et al. (2017). Exogenous miRNA-146a enhances the therapeutic efficacy of human mesenchymal stem cells by increasing vascular endothelial growth factor secretion in the ischemia/reperfusion-injured heart. J. Vasc. Res. 54, 100-108. doi: 10.1159/ 000461596

Serarslan, G., Altug, E., Kontas, T., Atik, E., and Avci, G. (2007). Caffeic acid phenethyl ester accelerates cutaneous wound healing in a rat model and decreases oxidative stress. Clin. Exp. Dermatol. 32, 709-715. doi: 10.1111/j. 1365-2230.2007.02470.x

Shahbazian, H., Yazdanpanah, L., and Latifi, S. M. (2013). Risk assessment of patients with diabetes for foot ulcers according to risk classification consensus of International Working Group on Diabetic Foot (IWGDF). Pak. J. Med. Sci. 29, 730-734. doi: 10.12669/pjms.293.3473

Shan, H., Zhang, Y., Lu, Y., Zhang, Y., Pan, Z., Cai, B., et al. (2009). Downregulation of miR-133 and miR-590 contributes to nicotine-induced atrial remodelling in canines. Cardiovasc. Res. 83, 465-472. doi: 10.1093/cvr/cvp130

Shilo, S., Roy, S., Khanna, S., and Sen, C. K. (2007). MicroRNA in cutaneous wound healing: a new paradigm. DNA Cell Biol. 26, 227-237. doi: 10.1089/dna.2006. 0568

Singh, P., Reimer, C. L., Peters, J. H., Stepp, M. A., Hynes, R. O., and Van De Water, L. (2004). The spatial and temporal expression patterns of integrin alpha9betal and one of its ligands, the EIIIA segment of fibronectin, in cutaneous wound healing. J. Invest. Dermatol. 123, 1176-1181. doi: 10.1111/j. 0022-202X.2004.23485.x

Siragam, V., Rutnam, Z. J., Yang, W., Fang, L., Luo, L., Yang, X., et al. (2012). MicroRNA miR-98 inhibits tumor angiogenesis and invasion by targeting activin receptor-like kinase- 4 and matrix metalloproteinase-11. Oncotarget 3, 1370-1385. doi: 10.18632/oncotarget.717
Sonkoly, E., Stahle, M., and Pivarcsi, A. (2008). MicroRNAs and immunity: novel players in the regulation of normal immune function and inflammation. Semin. Cancer Biol. 18, 131-140. doi: 10.1016/j.semcancer.2008.01.005

Sonkoly, E., Wei, T., Janson, P. C., Saaf, A., Lundeberg, L., Tengvall-Linder, M., et al. (2007). MicroRNAs: novel regulators involved in the pathogenesis of psoriasis? PLOS ONE 2:e610. doi: 10.1371/journal.pone.0000610

Stahlhut, C., Suarez, Y., Lu, J., Mishima, Y., and Giraldez, A. J. (2012). miR-1 and miR-206 regulate angiogenesis by modulating VegfA expression in zebrafish. Development 139, 4356-4364. doi: 10.1242/dev.083774

Sun, M., Chen, T., Patel, S., Ramchandran, R., and Raj, J. U. (2017). MicroRNA$133 \mathrm{a} / \mathrm{b}$ plays a role in hyperoxia-induced decreased lung vascularization and pulmonary hypertension in neonatal mice. Am. J. Respir. Crit. Care Med. 195:A6387.

Suzuki, S., Dobashi, Y., Hatakeyama, Y., Tajiri, R., Fujimura, T., Heldin, C. H., et al. (2010). Clinicopathological significance of platelet-derived growth factor (PDGF)-B and vascular endothelial growth factor-A expression, PDGF receptor- $\beta$ phosphorylation, and microvessel density in gastric cancer. $B M C$ Cancer 10:659. doi: 10.1186/1471-2407-10-659

Tan, B.-K., Tan, E., Chong, S.-J., Chang, Y.-Y., Song, C., and Lee, V. (2016). An economic evaluation of chronic wound management in a tertiary hospital. Wound Pract. Res. 24, 130-136.

Tan, Z., Jiang, H., Wu, Y., Xie, L., Dai, W., Tang, H., et al. (2014). miR185 is an independent prognosis factor and suppresses tumor metastasis in gastric cancer. Mol. Cell. Biochem. 386, 223-231. doi: 10.1007/s11010-013$1860-y$

Tatarano, S., Chiyomaru, T., Kawakami, K., Enokida, H., Yoshino, H., Hidaka, H., et al. (2011). miR-218 on the genomic loss region of chromosome 4p15. 31 functions as a tumor suppressor in bladder cancer. Int. J. Oncol. 39, 13-21. doi: 10.3892/ijo.2011.1012

Uesugi, A., Kozaki, K., Tsuruta, T., Furuta, M., Morita, K., Imoto, I., et al. (2011). The tumor suppressive microRNA miR-218 targets the mTOR component Rictor and inhibits AKT phosphorylation in oral cancer. Cancer Res. 71, 5765-5778. doi: 10.1158/0008-5472.CAN-11-0368

Valinezhad Orang, A., Safaralizadeh, R., and Kazemzadeh-Bavili, M. (2014). Mechanisms of miRNA-mediated gene regulation from common downregulation to mRNA-specific upregulation. Int. J. Genomics 2014:970607. doi: 10.1155/2014/970607

Varney, S. D., Betts, C. B., Zheng, R., Wu, L., Hinz, B., Zhou, J., et al. (2016). Hic- 5 is required for myofibroblast differentiation by regulating mechanically dependent MRTF-A nuclear accumulation. J. Cell Sci. 129, 774-787. doi: $10.1242 /$ jcs. 170589

Viticchie, G., Lena, A. M., Cianfarani, F., Odorisio, T., AnnicchiaricoPetruzzelli, M., Melino, G., et al. (2012). MicroRNA-203 contributes to skin re-epithelialization. Cell Death Dis. 3:e435. doi: 10.1038/cddis.2012.174

Wahid, F., Shehzad, A., Khan, T., and Kim, Y. Y. (2010). MicroRNAs: synthesis, mechanism, function, and recent clinical trials. Biochim. Biophys. Acta 1803, 1231-1243. doi: 10.1016/j.bbamcr.2010.06.013

Wang, A., Landen, N. X., Meisgen, F., Lohcharoenkal, W., Stahle, M., Sonkoly, E., et al. (2014). MicroRNA-31 is overexpressed in cutaneous squamous cell carcinoma and regulates cell motility and colony formation ability of tumor cells. PLOS ONE 9:e103206. doi: 10.1371/journal.pone.0103206

Wang, F. E., Zhang, C., Maminishkis, A., Dong, L., Zhi, C., Li, R., et al. (2010). MicroRNA-204/211 alters epithelial physiology. FASEB J. 24, 1552-1571. doi: 10.1096/fj.08-125856

Wang, J. M., Tao, J., Chen, D. D., Cai, J. J., Irani, K., Wang, Q., et al. (2014). MicroRNA miR-27b rescues bone marrow-derived angiogenic cell function and accelerates wound healing in type 2 diabetes mellitus. Arterioscler. Thromb. Vasc. Biol. 34, 99-109. doi: 10.1161/ATVBAHA.113.302104

Wang, N., Chen, C., Yang, D., Liao, Q., Luo, H., Wang, X., et al. (2017). Mesenchymal stem cells-derived extracellular vesicles, via miR-210, improve infarcted cardiac function by promotion of angiogenesis. Biochim. Biophys. Acta 1863, 2085-2092. doi: 10.1016/j.bbadis.2017.02.023

Wang, Q., Wang, Y., Minto, A. W., Wang, J., Shi, Q., Li, X., et al. (2008). MicroRNA-377 is up-regulated and can lead to increased fibronectin production in diabetic nephropathy. FASEB J. 22, 4126-4135. doi: 10.1096/fj. 08- 112326

Wang, T., Zhao, N., Long, S., Ge, L., Wang, A., Sun, H., et al. (2016). Downregulation of miR-205 in migrating epithelial tongue facilitates skin 
wound re-epithelialization by derepressing ITGA5. Biochim. Biophys. Acta 1862, 1443-1452. doi: 10.1016/j.bbadis.2016.05.004

Wang, Y., Li, W., Zang, X., Chen, N., Liu, T., Tsonis, P. A., et al. (2013a). MicroRNA-204-5p regulates epithelial-to-mesenchymal transition during human posterior capsule opacification by targeting SMAD4. Invest. Ophthalmol. Vis. Sci. 54, 323-332. doi: 10.1167/iovs.12-10904

Wang, Y., Zhang, X., Li, H., Yu, J., and Ren, X. (2013b). The role of miRNA-29 family in cancer. Eur. J. Cell Biol. 92, 123-128. doi: 10.1016/j.ejcb.2012.11.004

Wang, Y., Zhao, X., Shi, D., Chen, P., Yu, Y., Yang, L., et al. (2013c). Overexpression of SIRT1 promotes high glucose-attenuated corneal epithelial wound healing via 53 regulation of the IGFBP3/IGF-1R/AKT pathway. Invest. Ophthalmol. Vis. Sci. 54, 3806-3814. doi: 10.1167/iovs.13-12091

Watanabe, K., Hasegawa, Y., Yamashita, H., Shimizu, K., Ding, Y., Abe, M., et al. (2004). Vasohibin as an endothelium-derived negative feedback regulator of angiogenesis. J. Clin. Invest. 114, 898-907. doi: 10.1172/jci21152

Wei, W., He, H. B., Zhang, W. Y., Zhang, H. X., Bai, J. B., Liu, H. Z., et al. (2013). miR-29 targets Akt3 to reduce proliferation and facilitate differentiation of myoblasts in skeletal muscle development. Cell Death Dis. 4:e668. doi: 10.1038/ cddis.2013.184

Wellner, U., Schubert, J., Burk, U. C., Schmalhofer, O., Zhu, F., Sonntag, A., et al. (2009). The EMT-activator ZEB1 promotes tumorigenicity by repressing stemness-inhibiting microRNAs. Nat. Cell Biol. 11, 1487-1495. doi: 10.1038/ ncb1998

Xiao, K., Luo, X., Wang, X., and Gao, Z. (2017). MicroRNA-185 regulates transforming growth factor- $\beta 1$ and collagen- 1 in hypertrophic scar fibroblasts. Mol. Med. Rep. 15, 1489-1496. doi: 10.3892/mmr.2017.6179

Xie, M., Dart, D. A., Guo, T., Xing, X. F., Cheng, X. J., Du, H., et al. (2017). MicroRNA-1 acts as a tumor suppressor microRNA by inhibiting angiogenesisrelated growth factors in human gastric cancer. Gastric Cancer 21, 41-54. doi: 10.1007/s10120-017-0721-x

Xu, N., Meisgen, F., Butler, L. M., Han, G., Wang, X. J., Soderberg-Naucler, C., et al. (2013). MicroRNA-31 is overexpressed in psoriasis and modulates inflammatory cytokine and chemokine production in keratinocytes via targeting serine/threonine kinase 40. J. Immunol. 190, 678-688. doi: 10.4049/ jimmunol.1202695

Yamasaki, K., Nakasa, T., Miyaki, S., Ishikawa, M., Deie, M., Adachi, N., et al. (2009). Expression of MicroRNA-146a in osteoarthritis cartilage. Arthritis Rheum. 60, 1035-1041. doi: 10.1002/art.24404

Yan, B., Guo, Q., Fu, F. J., Wang, Z., Yin, Z., Wei, Y. B., et al. (2015). The role of miR-29b in cancer: regulation, function, and signaling. Onco Targets Ther. 8, 539-548. doi: 10.2147/OTT.S75899

Yang, W., and Yee, A. J. (2014). Versican $3^{\prime}$-untranslated region (3'UTR) promotes dermal wound repair and fibroblast migration by regulating miRNA activity. Biochim. Biophys. Acta 1843, 1373-1385. doi: 10.1016/j.bbamcr.2014.02.015

Yang, X., Wang, J., Guo, S. L., Fan, K. J., Li, J., Wang, Y. L., et al. (2011). miR-21 promotes keratinocyte migration and re-epithelialization during wound healing. Int. J. Biol. Sci. 7, 685-690. doi: 10.7150/ijbs.7.685

Yi, R., O’Carroll, D., Pasolli, H. A., Zhang, Z., Dietrich, F. S., Tarakhovsky, A., et al. (2006). Morphogenesis in skin is governed by discrete sets of differentially expressed microRNAs. Nat. Genet. 38, 356-362. doi: 10.1038/ ng1744

Yi, R., Poy, M. N., Stoffel, M., and Fuchs, E. (2008). A skin microRNA promotes differentiation by repressing 'stemness'. Nature 452, 225-229. doi: 10.1038/ nature 06642
Ying, X., Li-ya, Q., Feng, Z., Yin, W., and Ji-hong, L. (2015). MiR-939 promotes the proliferation of human ovarian cancer cells by repressing APC2 expression. Biomed. Pharmacother. 71, 64-69. doi: 10.1016/j.biopha.2015.02.020

Young, A., and McNaught, C.-E. (2011). The physiology of wound healing. Surgery 29, 475-479. doi: 10.1016/j.mpsur.2011.06.011

Yu, J., Peng, H., Ruan, Q., Fatima, A., Getsios, S., and Lavker, R. M. (2010). MicroRNA-205 promotes keratinocyte migration via the lipid phosphatase SHIP2. FASEB J. 24, 3950-3959. doi: 10.1096/fj.10-157404

Yu, J., Ryan, D. G., Getsios, S., Oliveira-Fernandes, M., Fatima, A., and Lavker, R. M. (2008). MicroRNA-184 antagonizes microRNA-205 to maintain SHIP2 levels in epithelia. Proc. Natl. Acad. Sci. U.S.A. 105, 19300-19305. doi: 10.1073/ pnas.0803992105

Zernecke, A., Bidzhekov, K., Noels, H., Shagdarsuren, E., Gan, L., Denecke, B., et al. (2009). Delivery of microRNA-126 by apoptotic bodies induces CXCL12dependent vascular protection. Sci. Signal. 2:ra81. doi: 10.1126/scisignal. 2000610

Zhang, J., Sun, X.-J., Chen, J., Hu, Z. W., Wang, L., Gu, D. M., et al. (2017). Increasing the miR-126 expression in the peripheral blood of patients with diabetic foot ulcers treated with maggot debridement therapy. J. Diabetes Complications 31, 241-244. doi: 10.1016/j.jdiacomp.2016.07.026

Zhang, L., Volinia, S., Bonome, T., Calin, G. A., Greshock, J., Yang, N., et al. (2008). Genomic and epigenetic alterations deregulate microRNA expression in human epithelial ovarian cancer. Proc. Natl. Acad. Sci. U.S.A. 105, 7004-7009. doi: 10.1073/pnas.0801615105

Zhang, L., Wang, X., and Chen, P. (2013). MiR-204 down regulates SIRT1 and reverts SIRT1-induced epithelial-mesenchymal transition, anoikis resistance and invasion in gastric cancer cells. BMC Cancer 13:290. doi: 10.1186/14712407-13-290

Zhang, R., Luo, H., Wang, S., Chen, W., Chen, Z., Wang, H. W., et al. (2014). MicroRNA-377 inhibited proliferation and invasion of human glioblastoma cells by directly targeting specificity protein 1. Neuro Oncol. 16, 1510-1522. doi: 10.1093/neuonc/noul11

Zhang, T., Jing, L., Li, H., Ding, L., Ai, D., Lyu, J., et al. (2017). MicroRNA-4530 promotes angiogenesis by targeting VASH1 in breast carcinoma cells. Oncol. Lett. 14, 111-118. doi: 10.3892/ol.2017.6102

Zhang, X., Dong, J., He, Y., Zhao, M., Liu, Z., Wang, N., et al. (2017). miR-218 inhibited tumor angiogenesis by targeting ROBO1 in gastric cancer. Gene 615, 42-49. doi: 10.1016/j.gene.2017.03.022

Zhu, Y., Li, Z., Wang, Y., Li, L., Wang, D., Zhang, W., et al. (2016). Overexpression of miR-29b reduces collagen biosynthesis by inhibiting heat shock protein 47 during skin wound healing. Transl. Res. 178, 38.e36-53.e36. doi: 10.1016/j.trsl. 2016.07.001

Conflict of Interest Statement: The authors declare that the research was conducted in the absence of any commercial or financial relationships that could be construed as a potential conflict of interest.

Copyright (c) 2018 Soliman, Das, Abd Ghafar and Teoh. This is an open-access article distributed under the terms of the Creative Commons Attribution License (CC BY). The use, distribution or reproduction in other forums is permitted, provided the original author(s) and the copyright owner are credited and that the original publication in this journal is cited, in accordance with accepted academic practice. No use, distribution or reproduction is permitted which does not comply with these terms. 